\title{
DYNAMICS OF A 4×6-METER THIN FILM ELLIPTICAL INFLATED MEMBRANE FOR SPACE APPLICATIONS
}

\author{
Matthew J. Casiano $†$ \\ Fluid Physics and Dynam ics Group/TD63 \\ Subsystem and Component Development Dept. \\ NASA Marshall Space Flight Center \\ Huntsville, AL 35.812
}

\author{
Hamid R. Hamidzadeh $\ddagger$ \\ South Dakota St. University \\ Mechanical Engineering Department \\ Brookings, South Dakota
}

\author{
Michael L. Tinker* \\ Structural Dynamics and Loads Group/ED21 \\ Sitructures, Mechanics, and Thermal Department \\ NASA Marshall Space Flight Center \\ Huntsville, AL 35812
}

\begin{abstract}
Dynamic characterization of a thin film inflatable elliptical structure is described in detail. A two-step finite element modeling approach in MSC/NASTRAN is utilized, consisting of (1) a nonlinear static pressurization procedure used to obtain the updated stiffness matrix, and (2) a modal "restart" eigen solution that uses the modified stiffness matrix.

Unique problems encountered in modeling of this large 4x6-meter lightweight inflatable ars identified, including considerable difficulty in obtaining convergence in the nonlinear finite element pressurization solution. It was found that the extremely thin polvimide film material (.001 in or 1 mil) presents tremendous problems in obtaining a converged solution when internal pressure loading is applied. Approaches utilized to overcome these difficulties are described.

Comparison of finite element predictions for frequency and mode shapes of the inflated structure with closed-form solutions for a flat pre-tensionec membrane indicate reasonable agreement.
\end{abstract}

\section{†Aerospace Technologist, \\ $\ddagger$ Professor of Mechanical Engineering; Fellow ASME \\ *Structural Dynamics Lead Engineer; Associate Fellow AIAA}

Copyright $\mathcal{\Theta} 2002$ by the American institute of Acronautics and Astronautics, Inc. No copyright is asserted in the United States under Title 17. U.S. Code. The I.S. government has a royalty-free license to exercise all rights under the copyright claimed herein for Governmental purfoses. All other rights are reserved by the copyright owner.

\section{Introduction and Background}

Inflatable structures have been the subject of renewed interest in recent years for space applications such as communications antennas, solar thermal propulsion, and space solar power (Figs. 1-2). A major advantage of using inflatable structures in space is their extremely light weight. An obvious second advantage is on-orbit deployability and subsequent space savings in the launch configuration. A recent technology demonstrator flight for inflatable structures was the Inflatable Antenna Experiment (IAE) that was deployed on orbit from the Shuttle Orbiter. Although difficulty was encountered in the inflation/deployment phase, the flight was successful overall and provided valuable experience in the use of such structures (Ref. 1).

The Solar Orbital Transfer Vehicle (SOTV), discussed in Ref. 2, and Solar Thermal Upper Stage (STUS), described in Refs. 3-5, are possible technology demonstrator flights for solar thermal propulsion. The basic concept behind solar thermal propulsion is to utilize sunlight or solar energy as a means of heating a working fluid (propellant) to provide thrust at increased specific impulse. As described in Ref. 6, thrust is produced by expanding the heated propellant through a nozzle. No combustion occurs, and the thrust level is low. For this reason, solar thermal propulsive systems are mainly applicable for orbital transfer vehicles. The engine system envisioned for the STUS is designed to utilize hydrogen propellant to produce a thrust level of about $2 \mathrm{lbf}$. Two inflatable parabolic collectors could be used that would be rotated and gimbaled for focusing sunlight into an absorber cavity (Fig. 1, from Ref. 5). The collectors would be inflated after separation of the upper stage from the launch vehicle.

Many investigators have considered the use of inflatable structures for space applications. Perhaps the earliest was Frei Otto (Ref. 7), who in 1962 published ideas for inflated tubular frames for use in structures such as orbiting platforms. A more recent proposed application involves the use of inflatable beam segments to replace 
solid segments of the Space Shuttle remote manipulator system and thus reduce storage space and inertia of the arm (Ref. 8).

Several papers on static structural analysis of inflated cylinders have been written, describing different techniques such as linear shell theory, and nonlinear and variational methods (Refs. 9-17), but very little work had been done in dynamics of inflatable structures until recent years. In 1988 Leonard (Ref. 18) indicated that elastic beam bending modes could be utilized in approximating lower-order frequencies of inflatable beams. Main, et al. wrote a very significant 1995 paper describing results of modal tests of inflated cantilever beams and the determination of effective material properties (Ref. 19). Changes in material properties for different pressures were also discussed, and the beam model was used in a more complex structure. The paper demonstrated that conventional finite element analysis packages could be very useful in the analysis of complex inflatable structures. Reference 20 describes an investigation of the dynamics of polyimide thin-film inflated cylinders, and Refs. 21-29 discuss recent dynamic tests/analyses and potential applications of inflatable solar concentrators.

\section{Description of Inflatable Concentrator Investigated in the Current Study}

In Fig. 3, a prototype elliptical, off-axis paraboloid 4x6-meter inflatable concentrator manufactured by SRS Technologies, Inc. is shown that consists of a pressurized lenticular supported by an aluminum fixture. The aluminum fixture will be supported by four I-beam stands for testing in a horizontal configuration. The inflatable is attached to the fixture by 204 silicon catenaries. The lenticular has a 226-in. major axis and a 164.08-in minor axis. This collector can function as a space-based antenna for communications, surveillance, and radiometry, or as a solar concentrator assembly for solar thermal propulsion systems. The inflatable lenticular element is constructed of NASA Langley Research Center's CP-1 which is .001 in (I mil) thick. Silicon-backed Kapton is the adhesive used for joints in the inflatable structures. A reflective coating on the inner lenticular CP-1 film provides the means of collecting radio waves or solar energy. It is noted that the particular application for the antenna/concentrator depends on the surface accuracy of the reflective lenticular surface. Use as an optical system would require greater surface accuracy than a solar concentrator for propulsion systems, for example.

In the case of solar thermal propulsion applications (Fig. 1), the collector assembly would focus sunlight into an absorber or secondary concentrator near the fixed ends of the struts. Solar energy stored in the absorber could be utilized to heat a propellant and generate thrust as described previously.

Inflatable structures in general are extremely lightweight and the collector described in this paper is no exception. The thin-film inflatable part of the concentrator weighs approximately $3 \mathrm{lb}$.

\section{Modeling Approach and Results}

The finite element modeling technique involved two main steps: 1. Nonlinear static analysis, in which the internal pressure loading was applied to the lenticular element and a pretension applied to the catenaries, and 2. modal analysis utilizing the results of step 1. Such a procedure is needed due to the impossibility of active forces in an eigensolution. In step 1, the stiffness matrix of the model is updated to capture the tensioning of the thin film material caused by internal pressure. This twostep modeling and analysis methodology is described in detail in Ref. 29, where results are given for inflatable cylindrical beams.

The lenticular film was modeled using NASTRAN quadrilateral plate elements, each of which were $.001 \mathrm{in}$. (1-mil) thick. Modulus, density, and Poisson's ratio as used were provided by the film manufacturers. The CP-1 film has $E=300 \mathrm{ksi}, v=0.34$, and $\rho=0.0518 \mathrm{lbm} / \mathrm{in}^{3}$. An internal pressure of 0.03 in. $\mathrm{H}_{2} \mathrm{O}(.00108 \mathrm{psig})$ was applied to the lenticular clement.

Modeling of the catenaries was done using silicon rod elements under a temperature load. The suggested temperature-loading pretension method was verified by comparing stress results to a rod with an applied force.

The Aluminum-5052 test fixture was also modeled using quadrilateral plate elements. The section of the aluminum plate with 3600 holes was modeled by altering the thickness accordingly to account for the adjusted density.

The steel I-beam stands were modeled using beam elements and multipoint constraints. A modal test was performed on a stand that was supported on three feet. The stands in the finite element model were cantileavered but were created with modes and mode shapes equivalent to that of the tested stand. Multipoint constraints were used to define a plate-sectioned rigid body in the place where the stand would be secured to the aluminum fixture. Fig. 4. shows the integrated finite element model.

Several parameter studies were performed to help diagnose problems and to aid in understanding of the solutions. Mode shapes and frequencies were compared while varying thickness, geometry, and material. Studies were also made on the effect of an induced strain or applied pressure. Drastic effects on mode shapes and frequencies would appear by changing only the geometry from elliptical-shaped to paraboloid-shaped. The introduction of curvature into the problem would not only affect system dynamics but also drastically increase computation time of the nonlinear static solution. It is interesting to point out that the strain of the paraboloid geometry (while averaging about $0.03 \%$ ) did have a varying value across the membrane due to the applied pressure. The flat elliptical model had an induced uniform strain of $0.03 \%$. But when a pressure was applied to the flat elliptical membrane giving a much greater and varying strain, the mode shapes were identical indicating that the mode shapes seem to be a function of geometry. The frequencies were not the same in this case. Ref. 30 shows that sag has played an 
interesting role in cables and cable trusses as shown. Fundamental natural frequencies of cables with a small amount of sag can be as much as $3010 \%$ more than those of a straight cable. Similar behavior may occur in membranes.

The greatest difficulty encountered in modeling and analysis was obtaining convergence of the nonlinear static pressurization solution in MSC/NASTRAN. This difficulty is due to the extremely thin polyimide material of which the inflatable components are constructed (1 mil or 1/1000 of one inch). The ratios of film thickness to overall geometric dimensions such as lenticular axes appear to be the critical parameters in the nonlinear pressurization analysis. For example, it was found that increasing the film thickness to 10 mils or $1 / 100$ in. resulted in solutions that converged easily. The reason for this phenomenon appears to be that extremely thin films tend to have large displacements and large stiffness changes when pressure loading is applied. Obviously, increased thickness reduces the inagnitude of these changes. Another issue in model convergence was finetuning the NASTRAN parameter 'kdiag'. A value of 'kdiag' helps convergence by initially adding a small value to the stiffness matrix diagonal terms and then is later removed. With this assistance, thers was convergence of iterations early on that normally would have trouble converging. The value of 'kdicg' was continually decreased until successive results would have similar solutions indicating no necessary further change in the parameter.

After all the difficulties encounte ed in this modeling and analysis effort, it was satisfying to obtain reasonable results. The first natural frequency of the integrated model was $7.87 \mathrm{~Hz}$, and the mode shape wils characterized by an up-and-down bobbing of the inflatale through the ring fixture as shown in Fig. 5. With the exception of the $4^{\text {th }}$ mode, the first seven modes exhibit rigid-body type modes due to the 204 catenaries that connec the inflatable to the fixture. Another example of these rigid-body type modes is shown in Fig. 6. These types of modes have frequencies not equal to zero but display motion in the directions of rigid body modes. A treathing mode of the entire inflatable occurs at $9.82 \mathrm{~Hz}$, which is the $4^{\text {th }}$ mode. The next system mode excluding the igid-body type mode (mode 8 ) occurs at $13.44 \mathrm{~Hz}$ chararterized as a $2^{\text {nd }}$-order breathing mode with node line along major axis of the inflatable. Table 1 shows some modes of the entire system. Some interesting curvature effects on the mode shape are apparent in mode $9(13.98 \mathrm{~Hz})$, Fig. 7. Coupled support structure and inflatable structure modes were seen for the first time at $26.15 \mathrm{~Hz}$ (mode 30) shown in Fig. 8.

\section{Comparison of Finite Element Results to Closed-Form Solutions}

The suggested method of applying a uniform strain to the membrane or a pretension to the catenaries is by using a change in temperature. This method was verified by comparing a catenary in strain to a catenary with an applied force. A 17.5-inch diameter membrane was tested and then modeled in NASTRAN using this technique. Results of another finite element analysis for this test were replicated. A strain of $0.2 \%$ due to dry shrinkage and other effects was found by comparing the test data with the model results.

A finite element model of the $4 \times 6$-meter inflatable membrane was modified (converted to a flat 2-D ellipse) and re-analyzed in MSC/NASTRAN. In this analysis, the support stand and ring fixture were not included in the model to allow a focus on the critical aspects of the modeling process and to allow comparison to closed form solutions. The pressure load was replaced by a uniform temperature-induced strain. The catenaries were also removed and the perimeter of the ellipse was fixed in all directions. Hamidzadeh's closed-form solution had the following conditions: flat elliptical membrane, zero displacement on the boundary, uniform strain, and CP-I properties. A nonlinear static analysis followed by a modal 'restart' was performed for this model as well.

The results are summarized in Table 2. The closed form solution compared well with the NASTRAN solution. The mode shapes were identical and the frequencies were on target. Slight differences in the frequencies can be attributed to approximate values for the Mathieu functions in the closed form solutions and slight geometric discrepancies in the NASTRAN model. A polynomial expansion for the Mathieu functions and modified Mathieu functions were used in calculating natural frequencies. The geometric dimensions in the NASTRAN model were slightly different then the design dimensions because the geometry followed that of the fabricated prototype.

\section{Summary}

Modeling of a large $4 \times 6-m$ thin-film inflatable concentrator structure has been accomplished. Comparisons with modal tests will be made at a later time. This work is significant because of (1) general difficulty in accurately representing the nonlinear material and geometric characteristics of these structures, (2) the large size of this thin-film structure, and most importantly, (3) the accomplishment of a modeling methodology that realistically represents the internal pressure loading and the stiffness properties of the thin films in a modal solution.

It was shown that many workarounds were required to obtain convergence of the nonlinear static pressurization procedure in MSC/NASTRAN. In this regard, MSC/NASTRAN was found to have limitations in its nonlinear analysis capability, particularly for large thinfilm structures of the type investigated in this paper. The use of ABAQUS or other finite element packages should also be considered for inflatable structures.

\section{Acknowledgments}

SRS Technologies is acknowledged for design and construction of the $4 \times 6-\mathrm{m}$ structure. Jennie McGee 
provided geometric and parameter information needed for modeling of the structure.

John Lassiter and Robert Engberg of Marshall Space Flight Center's Structural \& Dynamics 'Testing Group provided important modal test data.

\section{References}

1. Freeland, Robert E., "Inflatable Antenna Flight Experiment Experiences", NASA Solar Thermal Propulsion Workshop Proceedings, NASA Marshall Space Flight Center, Huntsville, AL, March 19-20, 1997.

2. Partch, Russell, "Solar Thermal Propulsion Program at Phillips Lab", NASA Solar Thermal Propulsion Workshop Proceedings, NASA Marshall Space Flight Center, Huntsville, AL March 19-20, 1997.

3. Stewart, Jesse F., and Martin, James A.,"Dual Fuel Solar Thermal Stage: Ideal Analysis", Journal of Spacecraft and Rockets, Vol. 33, No. 5, 1996, pp. 752754.

4. Patel, S., and Emrich, W. J., Jr., "Solar Thermal Upper Stage (STUS) Feasibility Study", Proceedings of ASME/JSME/JSES International Solar Energy Conference, Maui, HI, March 1995.

5. Hawk, C.W., Adams, Alan M., et al., "Conceptual Design of a Solar Thermal Upper Stage (STUS) Flight Experiment", AIAA Paper 95-2842.

6. Curtis, Leslie, "NASA Solar Thermal Propulsion Project", NASA Solar Thermal Propulsion Workshop Proceedings, NASA Marshall Space Flight Center, Huntsville, AL, March 19-20, 1997

7. Otto, Frei, Tensile Structures, Massachusetts Institute of Technology, Cambridge, MA, 1962.

8. McCarty, L.H., "Inflatable Arm Segments May Lighten Shuttle's Manipulator System", Design News 46(4), pp. 150-151, 1990.

9. Leonard, R.W., Brooks, G.W., and McComb, H.G., Jr., "Structural Considerations of Inflatable Reentry Vehicles", NASA Technical Note D-457, 1960.

10. Topping, A.D., "Shear Deflections and Buckling Characteristics of Inflated Members", Journal of Aircraft, 1(5), pp. 289-293, 1964.

11. Bulson, P.S., "Design Principles of Pneumatic Structures", Structural Engineering, 51(6), pp. 209-215. 1973.

12. Douglas, W.J., "Bending Stiffness of an Inflated Cylindrical Cantilever Beam", AIAA Journal, 7(7), pp. 1248-1253, 1969.

13. Steeves, E.C., "A Linear Analysis of the Deformation of Pressure Stabilized Tubes", U.S. Army Natick Laboratories Report, AD/A-006 493, NTIS, N75-32513.

14. Fichter, W.B., "A Theory for Inflated Thin-Wall Cylindrical Beams", NASA Technical Note D-3466, June 1966.

15. Comer, R.L., and Levy, S., "Deflections of an Inflated Circular-Cylinder Cantilever Beam", ALAA Journal, 1(7), pp. 1652-1655, 1963.
16. Webber, J.P.H., "Deflections of Inflated Cylindrical Cantilever Beams Subjected to Bending and Torsion", Acronautical Journal 86(858). pp. 306-312. 1982.

17. Main, J.A., Peterson, S.W., and Strauss, A.M., "Load-Deflection Behavior of Space-Based Inflatable Fabric Beams", Journal of Aerospace Engineering. 7(4), 1994.

18. Leonard, J.W., Tension Structures, McGrawHill, New York, 1988.

19. Main, J.A., Carlin, R.A., Garcia, E., Peterson, S.W., and Strauss, A.M., "Dynamic Analysis of SpaceBased Inflated Beam Structures", Journal of the Acoustical Society of America. 97(2), pp. 1035-1045. Feb. 1995

20. Slade, Kara N., and Tinker, Michael L., "Analytical and Experimental Investigation of the Dynamics of Polyimide Inflatable Cylinders", AIAA99-1518, Proceedings of the 40th Structures, Structural Dynamics, and Materials Conference, April 12-15, 1999, St. Louis, MO.

21. Tinker, Michael L., "Passively Adaptive Inflatable Structure for the Shooting Star Experiment", AIAA-98-1986, Proceedings of the 39th Structures, Structural Dynamics, and Materials Conference, April 20-23, 1998, Long Beach, CA.

22. Lassiter, John, "Shooting Star Experiment Prototype Inflatable Strut/Torus Assembly Modal Survey", ED73(97-69), NASA Marshall Space Flight Center, Huntsville, AL, June 1997.

23. Engberg, Robert, and Lassiter, John, "Shooting Star Experiment, Pathfinder 2, Inflatable Concentrator Modal Survey in Vacuum Conditions", Dynamics Test Branch, Marshall Space Flight Center Test Report SSE-DEV-ED97-120, March, 1998.

24. Engberg, Robert, and Lassiter, John, "Shooting Star Experiment, Pathfinder 3, Inflatable Concentrator Modal Survey in Thermal-Vacuum Conditions", Dynamics Test Branch, Marshall Space Flight Center Test Report SSE-DEV-ED97-115, February, 1998.

25. Engberg, Robert, and Lassiter, John, "Shooting Star Experiment, Pathfinder 3, Inflatable Concentrator Terminator Test, Dynamics Test Branch, Marshall Space Flight Center Test Report SSE-DEV-ED98-046, July, 1998.

26. Lassiter, John O., and Engberg, Robert, "Dynamic Testing of an Inflatable Structure Under Thermal-Vacuum Conditions", AlAA-99-1519, Proceedings of the 40th Structures, Structural Dynamics, and Materials Conference, April 12-15, 1999. St. Louis, MO.

27. Slade, Kara N., Tinker, Michael L., Lassiter, John O., and Engberg, Robert, "Comparison of Dynamic Characteristics for an Inflatable Solar Concentrator in Atmospheric and Thermal Vacuum Conditions", AIAA-2000-1641, Proceedings of the 41st Structures, Structural Dynamics, and Materials Conference, April 3-7, 2000, Atlanta, GA.

28. Slade, Kara N., "Dynamic Characterization of Thin Film Inflatable Structures", Ph.D. Dissertation, 
Duke University, Dept. of Mechanical Engineering and Materials Science, Durham, NC, 2000.

29. Smalley, Kurt B., Tinker, Michael L., and Fischer, Richard T., "Investigation of Nonlinear Pressurization and Modal Restart in MSC/NASTRAN for Modeling Thin Film Inflatable structures", AIAA2001-1409, Proceedings of the 42nd Structures, Structural Dynamics, and Materials Conference, April 16-19, 2001, Seattle, WA.

30. Blevens, Robert D. Formulas for Natural

Frequency and Mode Shape. New York: Van Nostrand Reinhold Co., 1979.

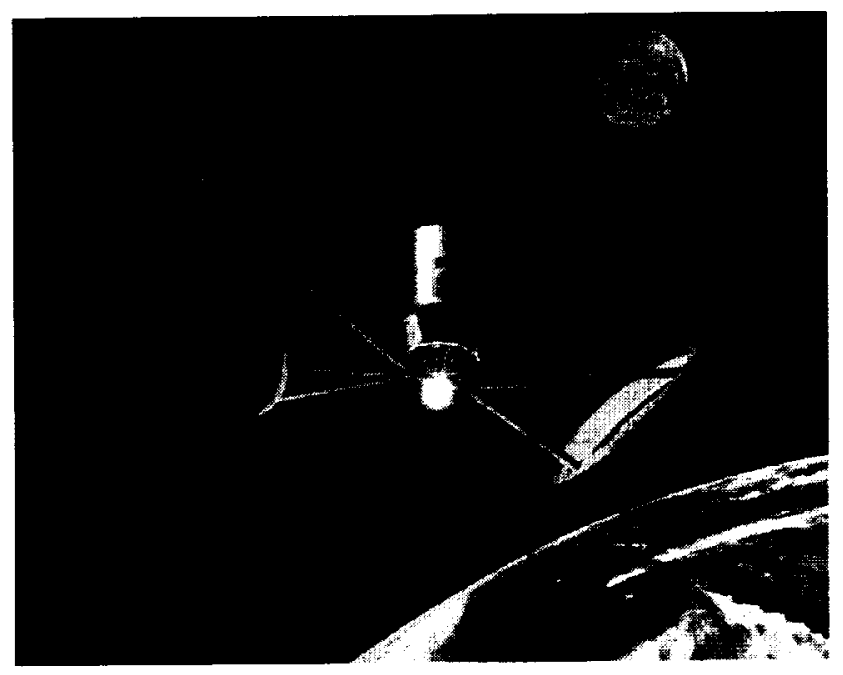

Figure 1. Concept for Solar Orbita Transfer Vehicle Utilizing Inflatable Solar Concentrators

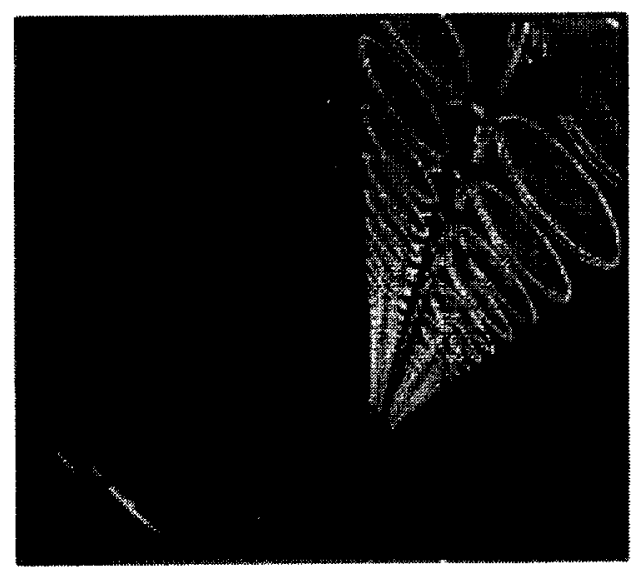

Figure 2. Space Solar Power Cc ncept Based on Inflatable Structurs:s

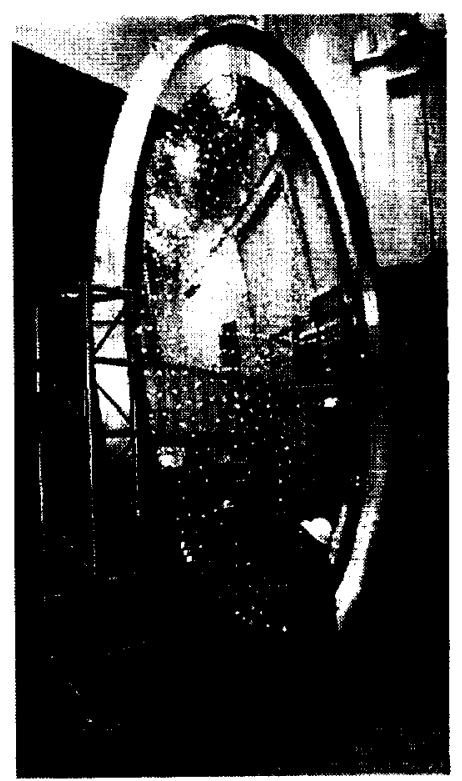

Figure 3. Vertically Supported 4x6-Meter Inflatable Concentrator with Aluminum Ring Fixture

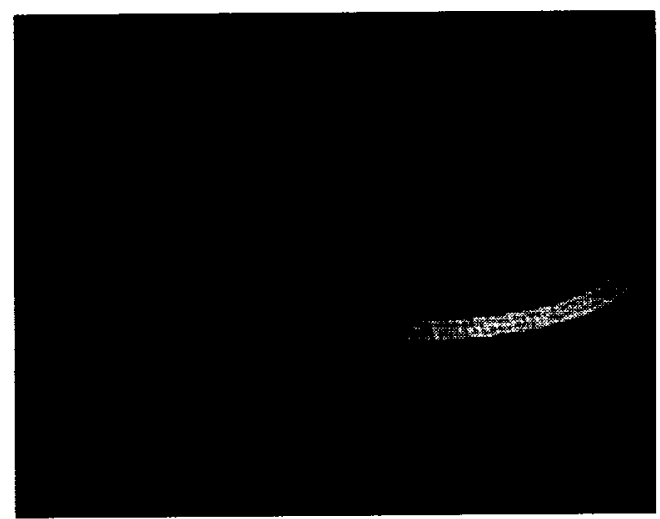

Figure 4. Finite Element Model Representation of Inflatable Collector and Supporting Structure

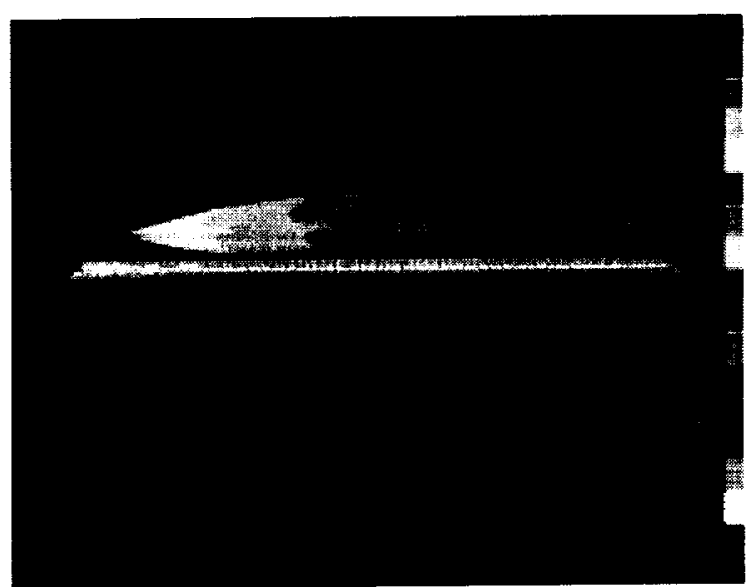

Figure 5. Fundamental Mode Shape Obtained in Finite Element Analysis $(7.87 \mathrm{~Hz}$ ) 


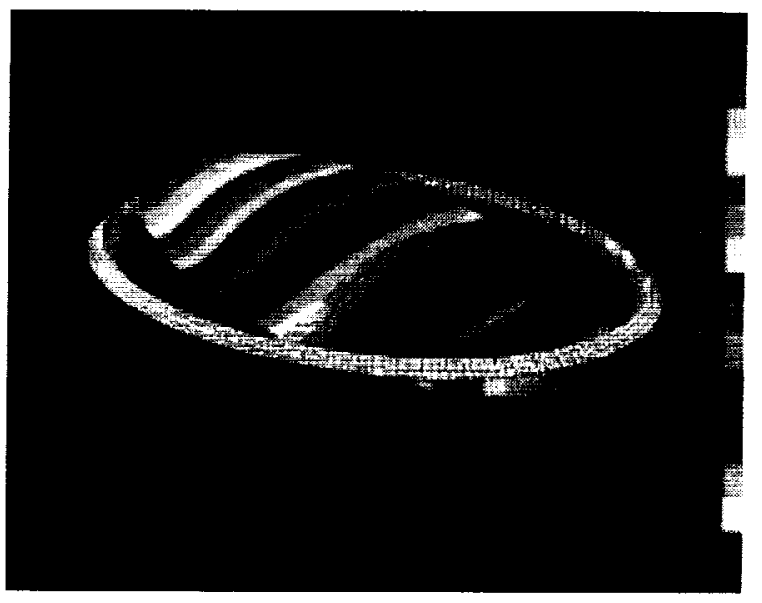

Figure 6. Rigid-Body Type Mode Shape Obtained in Finite Element Analysis (Mode 5, 10.34 Hz)

\begin{tabular}{|c|c|c|c|c|c|}
\hline $\begin{array}{c}\text { Mode } \\
\text { Number }\end{array}$ & $\begin{array}{c}\text { Freq } \\
(\mathrm{Hz})\end{array}$ & Node Lines & $\begin{array}{c}\text { Mode } \\
\text { Number }\end{array}$ & $\begin{array}{c}\text { Freq } \\
(\mathrm{Hz})\end{array}$ & Node Lines \\
\hline 1 & 7.87 & z-trans & 7 & 11.18 & z-rot \\
\hline 2 & 8.51 & x-trans & 8 & 13.44 & \\
\hline 3 & 8.58 & y-trans & 9 & 13.98 & \\
\hline 4 & 9.82 & ytros & 10 & 16.52 & \\
\hline 5 & 10.34 & y-rot & 11 & 16.54 & \\
\hline 6 & 10.95 & x-rot & 12 & 18.48 & \\
\hline
\end{tabular}

Table 1. Frequency Results for Finite Element Analysis of Concentrator and Support

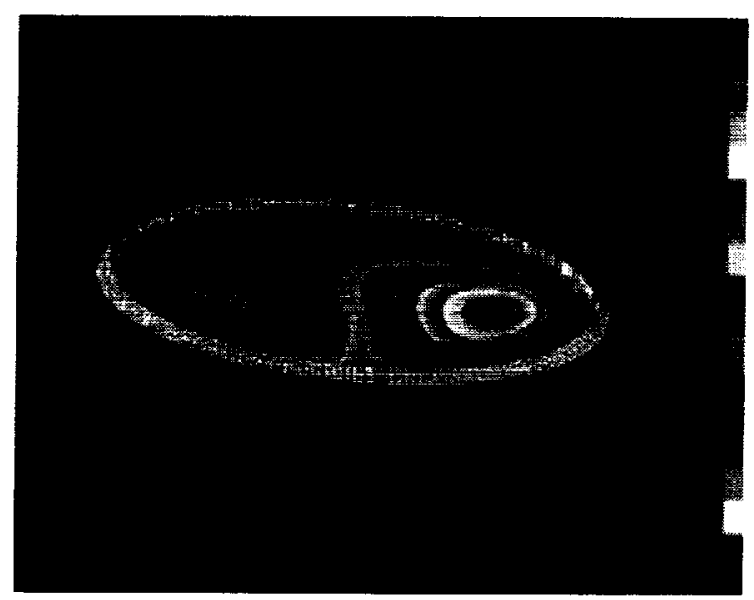

Figure 7. Mode $9(13.98 \mathrm{~Hz})$ Showing Geometric Curvature Effects on Mode Shape

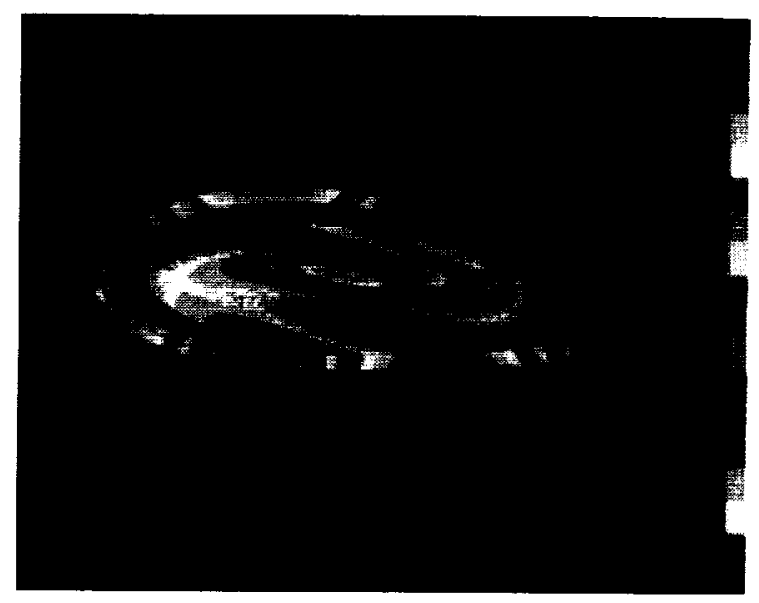

Figure 8. Coupling Between Support Structure and Inflatable at Mode $30(26.15 \mathrm{~Hz})$

\begin{tabular}{|c|c|c|c|}
\hline $\begin{array}{c}\text { Mode } \\
\text { Number }\end{array}$ & $\begin{array}{c}\text { Closed Form } \\
\text { Freq. }(\mathrm{Hz}) \\
\end{array}$ & $\begin{array}{l}\text { NASTRAN } \\
\text { Freq. }(\mathrm{Hz}) \\
\end{array}$ & Node Lines \\
\hline 1 & 4.1 & 4.2 & 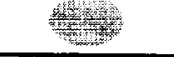 \\
\hline 2 & 5.9 & 6.2 & \\
\hline 3 & 7.0 & 7.3 & 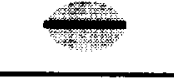 \\
\hline 4 & 7.5 & 8.3 & 4 \\
\hline 5 & 8.2 & 9.0 & \pm 1 \\
\hline
\end{tabular}

Table 2. Modes Predicted Using Finite Element Analysis and Closed Form Solutions for Flat Ellipse 